\title{
Characterization of Parental Lines and Land Races of Pearl Millet [Pennisetum glaucum (L) R. Br.] by DUS Descriptors
}

\author{
Venkataramana S Kalagare ${ }^{1 *}$, Meenakshi ganesan $\mathbf{N}^{1}$, Iyanar $\mathbf{K}^{\mathbf{2}}$, Chitdeshwari $\mathrm{T}^{\mathbf{3}}$ and Chandrasekhar $\mathbf{C} \mathbf{N}^{\mathbf{4}}$ \\ ${ }^{1 *}$ Department of Genetics and plant Breeding, Tamil Nadu Agricultural University, Coimbatore - 641003 \\ ${ }^{2}$ Department of Millets, Tamil Nadu Agricultural University, Coimbatore - 641003 \\ ${ }^{3}$ Department of Soil Science \& Agricultural Chemistry, Tamil Nadu Agricultural University, Coimbatore - 641003 \\ ${ }^{4}$ Department of Crop Physiology, Tamil Nadu Agricultural University, Coimbatore - 641003
}

\begin{abstract}
An experiment was conducted to characterize 31 pearl millet genotypes with 28 morphological traits using DUS descriptors at the Department of Millets, Tamil Nadu Agricultural University, Coimbatore, during Kharif 2019. The landrace Kizikuppam local was found to have a very long leaf length and a medium leaf width, indicating a high leaf area index, an important physiological trait that could be employed in future breeding programmes. The genotypes PT 6067, PT 6707, PT 6710, Cumbu 1, Uthangarai local and Shoolagiri local had compact panicle, an important ordinal trait for yield improvement. Small, yellow-brown color and elliptical shaped seeds were noted in Kuttu Cumbu 1, Kuttu Cumbu 2, Kuttu Cumbu 3, and Pothu Cumbu, which could be used to promote the variation in the base population. The early flowering nature of these genotypes might incorporate drought resistance. Agglomerative hierarchical cluster (AHC) analysis showed PT 6582, Kizikuppam local, Uthangarai local, and Dhanashakti were placed under cluster VI with maximum cluster mean for single plant yield. Superior classification of these genotypes for plant growth habit, leaf sheath length, leaf blade length, leaf blade width, panicle exertion, panicle length, panicle girth, number of productive tillers, plant height, panicle density and thousand seed weight indicated the importance of these ordinal traits in yield improvement by using the genotypes of this cluster. The Shannon-Wiener index was high for the time of spike emergence, thousand seed weight, leaf blade length, panicle shape, panicle density and seed color.
\end{abstract}

Keywords : Morphological Characterization; Diversity analysis; Cluster Analysis; Shannon-Wiener index (H); Pearl Millet

\section{INTRODUCTION}

Pearl millet [Pennisetum glaucum (L) R. Br.] is a prominent warm-season cereal crop grown on 260 lakh ha in the arid and semi-arid tropical regions of Asia (>100 lakh ha) and Africa (150-160 lakh ha). India is the largest producer (> 90 lakh ha) of the crop (Rai et al., 2009). Protogynous flowering nature evolved it into a highly cross-pollinated crop with an outcrossing rate of $85 \%$, which fulfills one of the essential biological requirements for hybrid development and open-pollinated varieties. It can adopt to diverse agro-ecological conditions and is mainly grown on marginal lands (Singh et al., 2016). Rajasthan is the largest producer of pearl millet in India with the production of 4.25 lakh tonnes, followed by Uttar Pradesh and Haryana (INDIASTAT, 2020).

Pearl millet has wide genetic diversity and *Corresponding author's e-mail: vkalagare@gmail.com adaptability. Hence, it is essential for genotype identification and classification using DUS morphological traits, which might help use specific genotypes in breeding programmes. These morphological traits help in differentiate the variety from the existing varieties and protect from infringement. To protect pearl millet varieties, one should prove the novelty among the DUS descriptor traits compared with existing varieties under a similar environment. Most of the qualitative traits are oligogenic and less influenced by the environment. Clear and distinct classification is possible with most of the qualitative traits. The trend of molecular characterization using molecular markers is also emerging and showed high polymorphism compared to morphological traits. Hence, there is a need for a more number of stable morphological traits to identify diversity in germplasm, differentiating the 
variety from the existing varieties and protecting from infringement. In this context, the present investigation was conducted on 31 pearl millet genotypes with the objective of characterization and diversity analysis with the help of morphological traits using frequency distribution and cluster analysis.

\section{MATERIAL AND METHODS}

A set of 31 pearl millet genotypes were used as experimental material, which included 17 restorers (R) lines (PT 6067, PT 6674, PT 6675, PT 6676, PT 6677, PT 6059, PT 6705, PT 6706, PT 6707, PT 6708, PT 6709, PT 6710, PT 6029 , PT 6580, PT 6581, PT 6582 and PT 6583), three maintainer (B) lines (ICMB 98222, ICMB 06111 and ICMB 99222), ten land races (Cumbu 1, Nattu Cumbu, Cumbu 2, Kuttu Cumbu 1, Kuttu Cumbu 2, Kuttu Cumbu 3, Kizikuppam local, Pothu Cumbu, Uthangarai local and Shoolagiri local) and an openpollinated variety (Dhanashakti). They were grown in Randomized Complete Block Design (RCBD) at the Department of Millets, Tamil Nadu Agricultural University, Coimbatore, during Kharif 2019. Each entry occupied a $3 \mathrm{~m}$ row with a spacing of $45 \mathrm{~cm}$ $\times 15 \mathrm{~cm}$. All agronomic practices were followed as per TNAU crop production guide. Observation on all 28 qualitative and quantitative traits wastaken and scored as per DUS (Distinct, Uniformity, and Stability) guidelines formulated for pearl millet by PPV\& FRA, 2001. Frequency distribution and graphical representation of various traits were worked out in MS Excel 2016. Gower's coefficient of similarity (Gower, 1971) measure was calculated among the genotypes and grouped into different clusters by agglomerative hierarchical cluster (AHC) method in STAR (Statistical Tool for Agricultural Research) software version 2.0.1 using 28 DUS descriptors and single plant yield. Plant growth habit, time of spike emergence, leaf sheath length, leaf blade length, leaf blade width, number of nodes, panicle exertion, panicle length, panicle girth, number of productive tillers, plant height, panicle density, and thousand seed weight were considered as an ordinal variable. Anthocyanin coloration of first leaf sheath, leaf sheath pubescence, stigma pigmentation, anther color, node pubescence, node pigmentation, internode pigmentation, anthocyanin pigmentation of glume, panicle bristle, panicle bristle color, panicle bristle appearance, panicle shape, panicle tip sterility, seed color, and seed shape were considered as the nominal variable and single plant yield as a numerical variable. Shannon-Wiener index $(H)$ (Shannon, 1948; Konopinski, 2020) of 28 DUS descriptors were computed in software PAST 4.0.

\section{RESULTS AND DISCUSSION}

Discrete morphological qualitative traits can be considered for the characterization of pearl millet genotypes. These traits can be observed with naked eyes. There is a need for more number of DUS traits for the classification and identification of individual genotypes.

Observation on 28 DUS traits was recorded and the frequency of genotypes was calculated in each class (Table 1). Most of the DUS traits showed at least two classes except for six traits like leaf sheath pubescence, stigma pigmentation, node pubescence, number of nodes, panicle bristle, and panicle bristle appearance, which showed no classification. This indicated the presence of diversity for observed morphological traits among the genotypes.

Around $67.74 \%$ of genotypes showed anthocyanin coloration of the first leaf sheath (Figure 1). Since anthocyanin pigment production was highly influenced by the environment, it was recommended to screen in controlled conditions. This trait is very important in the identification and purification of restorer and maintainer lines in a hybrid seed production programme (Kumar et al., 2020). The phenotypic characters related to pigmentation have been commonly used as genetic markers in plants to study diversity connected with evolution, tolerance to abiotic stress, and disease resistance (Varalakshmi et al., 2012). The time of spike emergence was very early in $60.29 \%$ of genotypes and early to medium in $19.35 \%$ genotypes. Pearl millet is grown mostly in low rain fall areas rather than areas having high agronomic potential. Hence, the drought escape mechanism (early flowering) is an essential criterion for pearl millet (Vadez et al., 2012). The landraces viz., Kuttu Cumbu 1, KuttuCumbu 2, Kuttu Cumbu 3, Kizikuppam local and Pothu Cumbu land races were in the early category exhibiting an essential drought escaping mechanism.

Twenty-two of genotypes had long leaf sheath (58.06\%) and medium leaf sheath length was observed in 12 genotypes, whereas short leaf sheath length was observed in one genotype. Leaf blade length was categorized into four groups, where maximum (51.61\%) genotypes came under the medium group and the other two, four, and nine genotypes came under long, very short and short categories, respectively (Figure 1). The selection of plants with long leaf sheath and leaf blade plays a vital role in yield increment (Kalagare et al., 2021, Vadez et al., 2012), because of early suppression of weeds and availability of more leaf area index for photosynthesis. In tilled soil, water use efficiency was high mainly due to an increase in the leaf area index and dry matter production, which were also essential traits of forage pearl millet (Crookston et al., 2020). The land race Kizikuppam local observed under very long leaf length category with medium leaf width can be utilized for improvement of leaf related traits in future breeding programmes. 
Table 1. Frequency distribution of morphological traits of pearl millet parental lines and land races

\begin{tabular}{|c|c|c|c|c|}
\hline $\begin{array}{l}\text { SI. } \\
\text { No. }\end{array}$ & Traits & Category & Number & Frequency \\
\hline \multirow{2}{*}{1} & \multirow{2}{*}{$\begin{array}{l}\text { Anthocyanin } \\
\text { coloration of first } \\
\text { leaf sheath (BLC) }\end{array}$} & Absent & 10 & 32.26 \\
\hline & & Present & 21 & 67.74 \\
\hline \multirow{3}{*}{2} & \multirow{3}{*}{$\begin{array}{l}\text { Plant growth } \\
\text { habit (PGH) }\end{array}$} & Erect & 4 & 12.90 \\
\hline & & Intermediate & 27 & 87.10 \\
\hline & & Spreading & 0 & 0.00 \\
\hline \multirow{5}{*}{3} & \multirow{5}{*}{$\begin{array}{l}\text { Time of spike } \\
\text { emergence (DTF) }\end{array}$} & $\begin{array}{l}\text { Very early }(<43 \\
\text { days) }\end{array}$ & 6 & 19.35 \\
\hline & & Early (43-46 days) & 2 & 6.45 \\
\hline & & Medium (47-50) & 9 & 29.03 \\
\hline & & Late (51-54 days) & 10 & 32.26 \\
\hline & & Very late (>54 days) & 4 & 12.90 \\
\hline \multirow{2}{*}{4} & \multirow{3}{*}{$\begin{array}{l}\text { Leaf sheath } \\
\text { pubescence (LSP) }\end{array}$} & Absent & 31 & 100.00 \\
\hline & & Present & 0 & 0.00 \\
\hline \multirow{3}{*}{5} & & Short $(<11)$ & 1 & 3.23 \\
\hline & \multirow{3}{*}{$\begin{array}{l}\text { Leaf sheath } \\
\text { length (LSL) }\end{array}$} & Medium (11-15) & 8 & 25.81 \\
\hline & & Long (>15) & 22 & 70.97 \\
\hline \multirow{5}{*}{6} & & Very short $(<41)$ & 3 & 9.68 \\
\hline & \multirow{4}{*}{$\begin{array}{l}\text { Leaf blade length } \\
(\mathrm{LBL})\end{array}$} & Short (41-50) & 6 & 19.35 \\
\hline & & Medium (51-60) & 12 & 38.71 \\
\hline & & Long (61-70) & 9 & 29.03 \\
\hline & & Very long (>70) & 1 & 3.23 \\
\hline \multirow{3}{*}{7} & \multirow{3}{*}{$\begin{array}{l}\text { Leaf blade width } \\
\text { (LBW) }\end{array}$} & Narrow $(<3)$ & 2 & 6.45 \\
\hline & & Medium (3-4) & 29 & 93.55 \\
\hline & & Broad $(>4)$ & 0 & 0.00 \\
\hline \multirow{3}{*}{8} & \multirow{3}{*}{$\begin{array}{l}\text { Stigma } \\
\text { pigmentation (SC) }\end{array}$} & Absent & 31 & 100.00 \\
\hline & & Present & 0 & 0.00 \\
\hline & & Yellow & 13 & 41.94 \\
\hline \multirow[t]{2}{*}{9} & \multirow[t]{2}{*}{ Anther color (AC) } & Brown & 0 & 0.00 \\
\hline & & Purple & 18 & 58.06 \\
\hline \multirow{2}{*}{10} & \multirow{3}{*}{$\begin{array}{l}\text { Node pubescence } \\
\text { (NP) }\end{array}$} & Absent & 31 & 100.00 \\
\hline & & Present & 0 & 0.00 \\
\hline \multirow{3}{*}{11} & & Low $(<11)$ & 0 & 0.00 \\
\hline & $\begin{array}{l}\text { Number of nodes } \\
\text { (NN) }\end{array}$ & Medium (11-15) & 31 & 100.00 \\
\hline & & High (>15) & 0 & 0.00 \\
\hline & & Whitish & 0 & 0.00 \\
\hline & Node & Green & 20 & 64.52 \\
\hline 12 & pigmentation & Brown & 3 & 9.68 \\
\hline & $(\mathrm{NC})$ & Red & 0 & 0.00 \\
\hline & & Purple & 8 & 25.81 \\
\hline & & Whitish & 0 & 0.00 \\
\hline & Internode & Green & 23 & 74.19 \\
\hline 13 & pigmentation & Brown & 0 & 0.00 \\
\hline & $(\mathrm{INC})$ & Red & 0 & 0.00 \\
\hline & & Purple & 8 & 25.81 \\
\hline & & Incomplete & 0 & 0.00 \\
\hline 14 & $\begin{array}{l}\text { Panicle exertion } \\
(\mathrm{PE})\end{array}$ & Partial & 5 & 16.13 \\
\hline & & Complete & 26 & 83.87 \\
\hline & & Very small $(<11)$ & 0 & 0.00 \\
\hline & & Small (11-20) & 10 & 32.26 \\
\hline 15 & Panicle length & Medium (21-30) & 18 & 58.06 \\
\hline & & Long (31-40) & 3 & 9.68 \\
\hline & & Very long (>40) & 0 & 0.00 \\
\hline
\end{tabular}

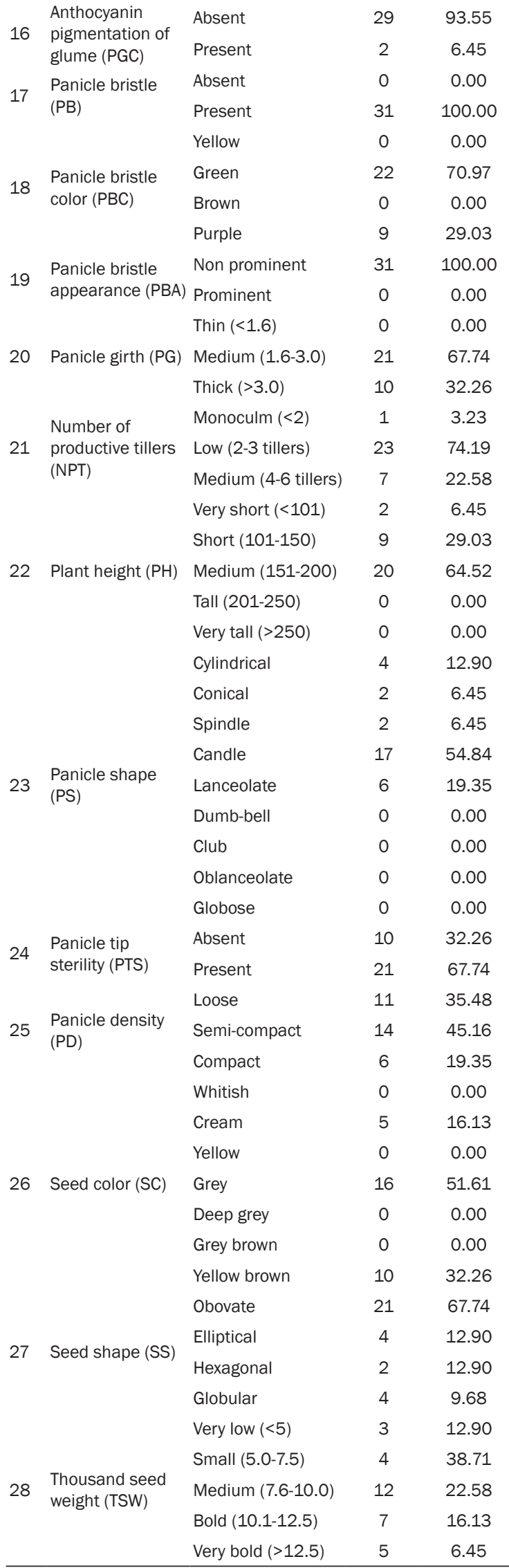


Figure 1. Graphical representation of frequency distribution of various morphological traits of pearl millet parental lines and land races
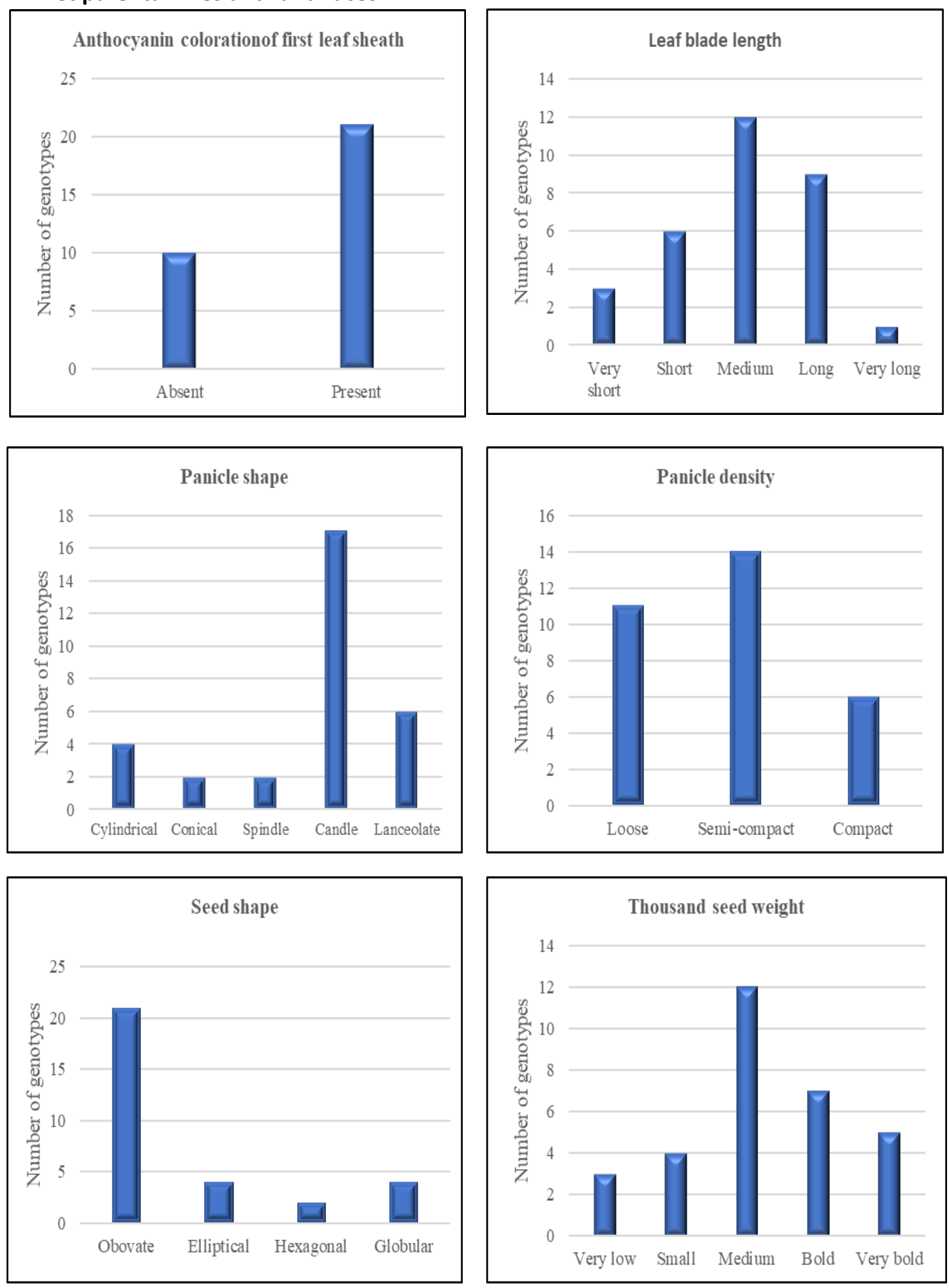
Anther color was observed in two categories. Fifty-eight percent of genotypes were purple colored and the remaining were yellow colored. This trait was important for the purification and identification of parental lines in the hybrid seed production programme. Medium panicle length between $21 \mathrm{~cm}$ to $30 \mathrm{~cm}$ was prominent in the population and others belonged to small (4) and long categories (1). A maximum number of genotypes showed medium panicle girth, while two genotypes had a thin panicle and 12 had a thick panicle. About $74.19 \%$ of genotypes came under the low number of productive tillers category and the rest had monoculed (one) and medium number of productive tillers (two). Reports of landraces with plant types having profuse tillering and small panicles were found to produce higher grain yield than the plant type having low tillering and large panicles under severe moisture stress (Van Oosterom et al., 2006). The number of productive tillers was almost single for the genotype PT 6059.

Table 2. Estimates of descriptive statistics of different clusters based on single plant yield as numerical variable of 31 pearl millet genotypes

\begin{tabular}{|c|c|c|c|c|c|}
\hline \multirow{2}{*}{ Cluster group } & \multicolumn{4}{|c|}{ Single plant yield (g) } & \multirow{2}{*}{ Genotypes } \\
\hline & Min & Max & Mean & Std Dev & \\
\hline Cluster I & 31.58 & 86.17 & 52.18 & 17.67 & $\begin{array}{l}\text { PT 6067, PT 6675, PT 6705, PT 6707, PT 6029, PT 6580, PT 6583, Cumbu } \\
\text { 1, Nattu Cumbu, Cumbu } 2 \text { and Shoolagiri local }\end{array}$ \\
\hline Cluster II & 31.83 & 38.1 & 34.97 & 4.43 & PT 6674 and PT 6709 \\
\hline Cluster III & 25.3 & 71.94 & 44.92 & 16.02 & PT 6676, PT 6677, PT 6710, PT 6581, ICMB 98222 and ICMB 99222 \\
\hline Cluster IV & 19.2 & 19.2 & 19.2 & & РT 6059 \\
\hline Cluster V & 48.56 & 74.49 & 61.52 & 18.34 & PT 6706 and PT 6708 \\
\hline Cluster VI & 55.14 & 79 & 69.02 & 10.21 & PT 6582, Kizikuppam local, Uthangarai local and Dhanashakti \\
\hline Cluster VII & 43.45 & 43.45 & 43.45 & & ICMB 06111 \\
\hline Cluster VIII & 26.37 & 35.85 & 30.63 & 4.04 & Kuttu Cumbu 1, Kuttu Cumbu 2, Kuttu Cumbu 3 and Pothu Cumbu \\
\hline
\end{tabular}

Plant height was categorized into four groups and larger number of genotypes (64.52\%) fell under the medium group. Very short plant height was observed in PT 6059 and ICMB 06111. Candle-shaped panicle (54.84\%) was prominent as compared to cylindrical, conical, spindle and lanceolate type (Figure 1). About $44.16 \%$ of genotypes came under semi-compact panicle density group and rest of the genotypes were loose (11) and compact (6) (Figure 1). The genotypes viz. PT 6067, PT 6707, PT 6710, Cumbu 1 , Uthangarai local and Shoolagiri local were with compact panicle, which is one of the important ordinal traits for yield improvement.

Out of 31 genotypes, 16 genotypes showed grey color grains, whereas the grains of five and ten genotypes were of cream and yellow yellow-brown color. Grey grain colored hybrids exhibited a negative correlation for starch and fats, while white grain color hybrids resulted ina significant correlation for starch (Arya et al., 2009). Most of the genotypes (67.74\%) fell under obovate seed shape and the rest of them were elliptical (4), hexagonal (2), and globular shaped (4) (Figure 1). Observation of thousand seed weight showed that the maximum number of genotypes had bold seed (13). Very low, small, medium, and very bold seeds possessed two, three, twelve, and one genotype, respectively (Figure 1). Significant association of iron and zinc with thousand seed weight indicated that bold size seed would have more iron and zinc (Gupta et al., 2009). PT 6706, PT 6029, PT 6581, Cumbu 2, and Dhanashakti came under the very bold seed group and can be utilized for the biofortification programme.

The four land races, Kuttu Cumbu 1, Kuttu Cumbu 2, Kuttu Cumbu 3, and Pothu Cumbu were smallseeded, yellow-brown colored with elliptical shaped seeds. Most of the $\mathrm{R}$ lines were bold seeded with grey color. B lines were comparatively small-seeded compared to $\mathrm{R}$ lines and short plants. Comparison of seeds of these genotypes with R line (PT 6067), B line (ICMB 06111), and Dhanashakthi were depicted in Figure 2. Even though grain color did not influence the grain iron and zinc density (Govindaraj et al., 2018 ), grain size was influencing the grain iron and zinc density (Kanatti et al., 2019). 
a). Land races (Seeds are Yellow brown colored, Elliptical in shape and Small sized)

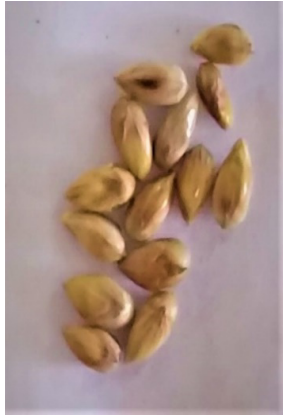

Name: KuttuCumbu 1

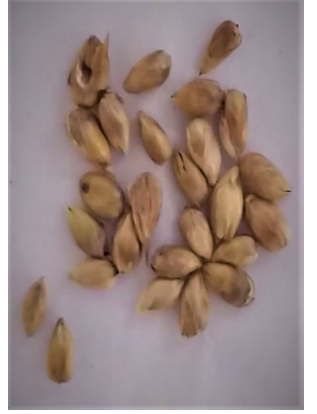

Name: KuttuCumbu 2

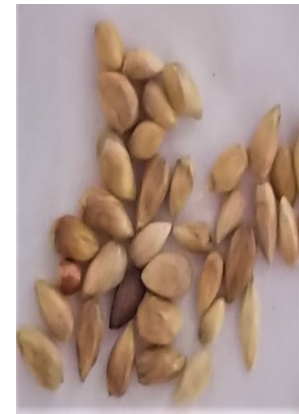

Name: KuttuCumbu 3

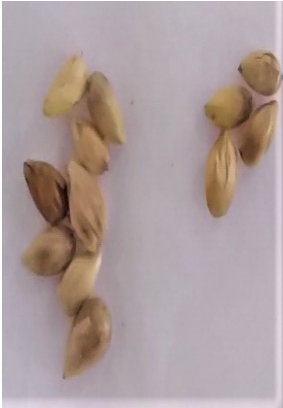

Name: PothuCumbu b). Restorer line

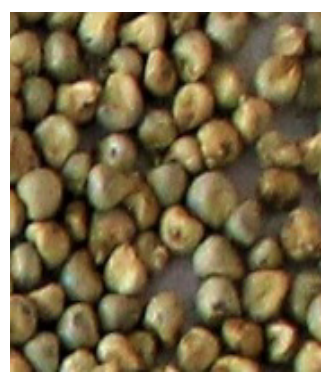

Name: PT 6067

Color: Grey

Shape: Obovate

Size: Bold c). Maintainer line

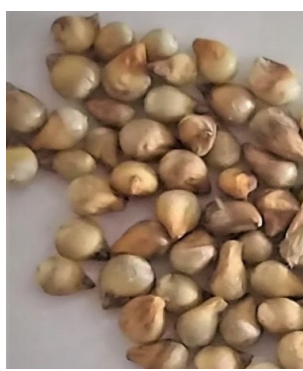

Name: ICMB 06111

Color: Yellow brown

Shape: Globular

Size: Small d). Open pollinated variety

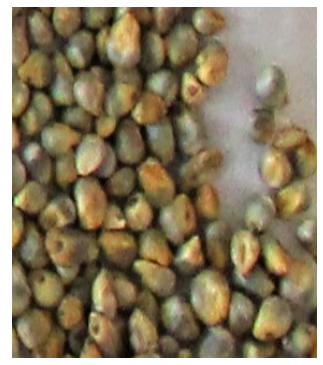

Name: Dhanashakti

Color: Grey

Shape: Obovate

Size: Vev bold

\section{Figure 2. Representation of diversity of pearl millet parental lines and land races in terms of seed color} and seed shape

Cluster analysis using the agglomerative hierarchical cluster (AHC) approach revealed eight clusters depicted in a dendrogram (Figure 3). The cophenetic correlation coefficient measures of how faithfully a dendrogram preserves the pairwise distances between the original unmodeled data points. The cophenetic correlation coefficient of 0.649 for cluster analysis, was found to indicate the accuracy and stability of the hierarchical clustering results (Shah et al., 2013, Azevedo et al., 2012). Gower's similarity coefficient permits the simultaneous use of variables of different scales of measurement in the estimation of similarity. From the dendrogram, it was observed that the clusters were formed at around Gower's similarity coefficient of 0.3. A maximum number of genotypes (11) were under cluster I followed by cluster III, cluster VI, cluster VIII, cluster II, cluster V, cluster IV and cluster VII, and the seclusters had six, four, four, two, two, one and one genotypes respectively.

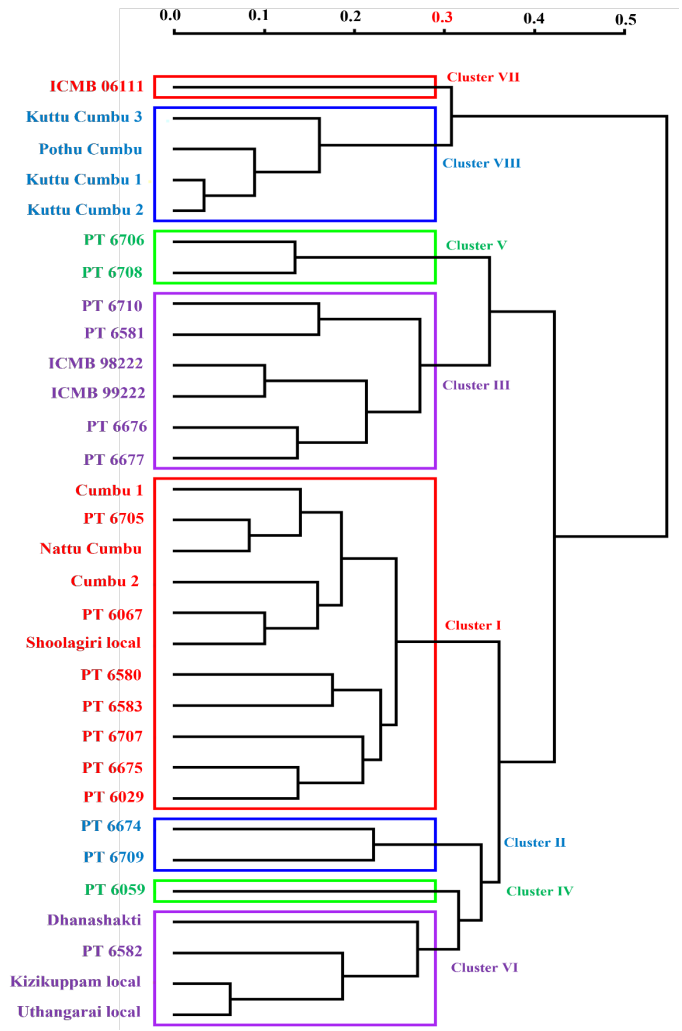

Figure 3. Dendrogram depicting the nine clusters among 31 pearl millet genotypes using UPGMA method of clustering 
Descriptive statistics of single plant yield on different clusters were presented in Table 2. The highest cluster mean of single plant yield was observed for cluster VI (69.02), followed by cluster V and cluster I. The least cluster means of single plant yield 19.2 g was observed for cluster IV, followed by cluster VIII and cluster II. Cluster VI genotypes (PT 6582, Kizikuppam local, Uthangarai local, and Dhanashakti) showed higher-order classification for ordinal variables like plant growth habit, leaf sheath length, leaf blade length, leaf blade width, panicle exertion, panicle length, panicle girth, number of productive tillers, plant height, panicle density and thousand seed weight. They indicated the usefulness of the selection of these traits in the improvement of yield. The cluster $V$ genotypes (PT 6706 and PT 6708) also showed similar kind of pattern for ordinal variables.

Table 3. Shannon-Wiener index $(H)$ for 28 morphological traits of $\mathbf{3 1}$ pearl millet genotypes

\begin{tabular}{|c|c|c|}
\hline Characters & Abbreviations & $\boldsymbol{H}$ \\
\hline $\begin{array}{l}\text { Anthocyanin coloration of } \\
\text { first leaf sheath }\end{array}$ & BLC & 0.629 \\
\hline Plant growth habit & PGH & 0.385 \\
\hline Time of spike emergence & DTF & 1.483 \\
\hline Leaf sheath pubescence & LSP & 0.000 \\
\hline Leaf sheath length & LSL & 0.704 \\
\hline Leaf blade length & LBL & 1.381 \\
\hline Leaf blade width & LBW & 0.239 \\
\hline Stigma pigmentation & SC & 0.000 \\
\hline Anther color & $\mathrm{AC}$ & 0.680 \\
\hline Node pubescence & NP & 0.000 \\
\hline Number of nodes & NN & 0.000 \\
\hline Node pigmentation & $\mathrm{NC}$ & 0.858 \\
\hline Internode pigmentation & INC & 0.571 \\
\hline Panicle exertion & $\mathrm{PE}$ & 0.442 \\
\hline Panicle length & $\mathrm{PL}$ & 0.907 \\
\hline $\begin{array}{l}\text { Anthocyanin pigmentation } \\
\text { of glume }\end{array}$ & PGC & 0.239 \\
\hline Panicle bristle & $\mathrm{PB}$ & 0.000 \\
\hline Panicle bristle color & $\mathrm{PBC}$ & 0.602 \\
\hline Panicle bristle appearance & PBA & 0.000 \\
\hline Panicle girth & $P G$ & 0.629 \\
\hline Number of productive tillers & NPT & 0.668 \\
\hline Plant height & $\mathrm{PH}$ & 0.819 \\
\hline Panicle shape & PS & 1.265 \\
\hline Panicle tip sterility & PTS & 0.629 \\
\hline Panicle density & PD & 1.044 \\
\hline Seed color & SC & 1.001 \\
\hline Seed shape & SS & 0.969 \\
\hline Thousand seed weight & TSW & 1.454 \\
\hline
\end{tabular}

The small-seeded land races Kuttu Cumbu 1, Kuttu Cumbu 2, Kuttu Cumbu 3, and Pothu Cumbu differed significantly from the other genotypes and were found in cluster VIII. These land races were of early flowering and had small panicles with small seeds with more tillers and also showed an early time of spike emergence, which is one of the droughts escaping mechanisms (Vadez et al., 2012).

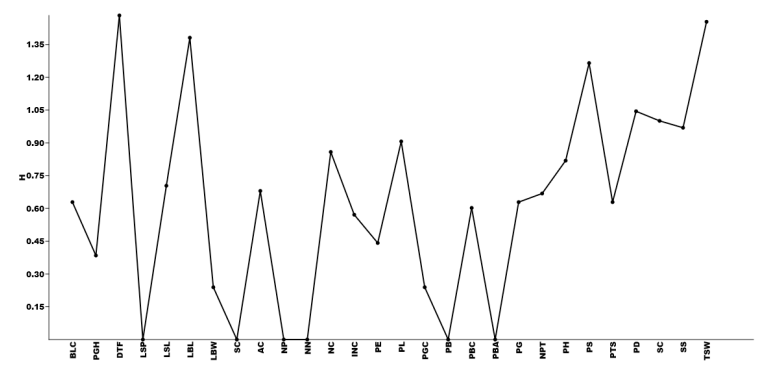

Figure 4. Graphical representation of ShannonWiener index $(H)$ among 28 morphological traits

Shannon-Wiener index $(H)$ is a measure that reflects the number of different species and how evenly the individuals are distributed among those species. The Shannon-Wiener index $(\mathrm{H})$ of various traits ranging from zero to 1.483 was depicted in Table 3 and Figure 4. The highest Shannon-Wiener index $(H)$ value of 1.483 was observed for the time of spike emergence, followed by thousand seed weight (1.454), leaf blade length (1.381) and spike shape (1.265), spike density (1.044) and seed color (1.001). The leastShannon-Wiener index $(H)$ value of zero was observed for leaf sheath pubescence, stigma pigmentation, node pubescence, number of nodes, spike bristle and bristle appearance indicated that there existed no diversity among these traits in given experimental material. A higher value of indices indicates the presence of more diversity of genotypes for a particular trait (Upadhyaya et al., 2002). The result indicated that time of spike emergence, thousand seed weight, leaf blade length and spike shape, spike density, and seed color showed significant diversity in the traits, which can be exploited to improve of these traits.

\section{CONCLUSION}

From the above results, it was observed that there was significant diversity among the genotypes with respect to morphological traits. Anthocyanin coloration of first leaf sheath, anther color, node color and internodal colors were easy observable traits and were utilized in the rouging of off type in hybrid seed production programme. The land race Kizikuppam local observed under very long leaf length category with medium leaf width indicated high leaf area index, an important physiological trait which could be utilized for the future breeding 
programme. The number of productive tillers was almost single for the genotype PT 6059. The genotypes PT 6067, PT 6707, PT 6710, Cumbu 1, Uthangarai local, and Shoolagiri local with compact panicle is one of the important ordinal traits for yield improvement. PT 6706, PT 6029, PT 6581, Cumbu 2 , and Dhanashakti came under the very bold seed group, with direct influence on the yield. Four land races (Kuttu Cumbu 1, Kuttu Cumbu 2, Kuttu Cumbu 3 and Pothu Cumbu) showed distinct characteristics for small, yellow-browncolored and elliptical shaped seeds, which could be used to promote the variation of the base population and early flowering might be used to incorporate drought escape mechanism. Agglomerative hierarchical cluster (AHC) analysis resulted in eight clusters and showed Gower's similarity coefficient of 0.3 . Cluster I showed a maximum of 11 genotypes. PT 6582, Kizikuppam local, Uthangarai local, and Dhanashakti showed maximum cluster means for single plant yield. They fell under superior category for the traits plant growth habit, leaf sheath length, leaf blade length, leaf blade width, panicle exertion, panicle length, panicle girth, number of productive tillers, plant height, panicle density and thousand seed weight. This indicated the importance of these ordinal traits in yield improvement utilizing the genotypes of this cluster. The small-seeded land races Kuttu Cumbu 1, Kuttu Cumbu 2, Kuttu Cumbu 3, and Pothu Cumbu differed significantly from the other genotypes and were found in cluster VIII. The Shannon-Weaver diversity index was found to be high for the time of spike emergence, thousand seed weight, leaf blade length and panicle shape, panicle density and seed color, indicating the existence of high variability in the material studied.

\section{Funding and Acknowledgment}

The authors acknowledge the financial support provided by Tamil Nadu Agriculture University, Coimbatore and also acknowledges the department of Plant Genetic Resources, TNAU, Coimbatore, for providing the seeds of pearl millet land races.

\section{Ethics statement}

No specific permits were required for the described field studies because no human or animal subjects were involved in this research.

\section{Consent for publication}

All the authors agreed to publish the content.

\section{Competing interests}

There were no conflict of interest in the publication of this content

\section{REFERENCES}

Arya R. K., Yadav H. P. 2009. Stability of grain yield and its contributing traits in white and grey grain hybrids in bajra. Indian J. Agric. Sci., 79: 941-944.

Azevedo, A. L. S., Costa, P. P., Machado, J. C., Machado, M. A., Vander Pereira, A. and da Silva Lédo, F. J. 2012. Cross species amplification of Pennisetum glaucum microsatellite markers in Pennisetum purpureum and genetic diversity of Napier grass accessions. Crop Sci., 52(4): 1776.

Crookston, B., Blaser, B., Darapuneni, M. and Rhoades, M. 2020. Pearl Millet Forage Water Use Efficiency. Agron., 10(11): 1672.

Govindaraj, M., Rao, A. S., Shivade, H. and Rai, K. N. 2018. Effect of grain color on iron and zinc density in pearl millet. Indian J. Genet. Plant Breed., 78(2): 247-251.

Gower, J. C., 1971. A general coefficient of similarity and some of its properties. Biometrics, 27: 857-871.

Gupta, S. K., Velu, G., Rai, K. N. and Sumalini, K. 2009. Association of grain iron and zinc content with grain yield and other traits in pearl millet (Pennisetum glaucum (L.) R. Br.). Crop Improv., 36(2): 4-7.

Kalagare, V. S., Ganesan, N. M., Iyanar, K., Chitdeshwari, T. and Chandrasekhar, C. N. 2021. Strategy of multiple selection indices for discrimination of potential genotypes and associated traits for yield improvement in pearl millet [Pennisetum glaucum (L.) R. Br.]. Electron. J. Plant Breed., 12(3): 895906.

Kanatti, A., Rai, K. N., Radhika, K., Govindaraj, M., Sahrawat, K. L. and Rao, A. S. 2014. Grain iron and zinc density in pearl millet: combining ability, heterosis and association with grain yield and grain size. Springerplus, 3(1): 1-12.

Konopinski, M. K. 2020. Shannon diversity index: a call to replace the original Shannon's formula with unbiased estimator in the population genetics studies. Peer J., 8: 9391.

Kumar M., Rani K., Ajay B. C., Patel M. S., Mungra K. D. and Patel M. P. 2020. Multivariate diversity analysis for grain micronutrients concentration, yield and agromorphological traits in pearl millet (Pennisetum glaucum (L) R Br). Int. J. Curr. Microbiol. Appl. Sci., 9(3): 2209-2226.

Rai, K. N., Gupta, S. K., Ranjana, B., Kulkarni, V. N., Singh, A. K. and Rao, A. S. 2009. Morphological characteristics of ICRISAT-bred pearl millet hybrid seed parents.J. SAT Agric. Res., 7:176.

Shah, A. K., Ravikiran, R., Litoriya, N. S., Patel, H. K. and Talati, J. G. 2013. Validation of genetic purity among hybrid lines in pearl millet (Pennisetum glaucum L.) using RAPD and SSR markers. Indian J. Agric. Biochem., 26(2): 172-176.

Shannon C. E. 1948. A mathematical theory of communication. Bell Syst. tech. j., 27: 379-423

Singh, S., Yadav, Y. P., Yadav, H. P., Vart, D. and Yadav, N. 2016. Morphological characterization of pearl millet hybrids [Pennisetum glaucum (L.) R. Br.] and their parents. Afr. J. Agric. Res., 11(5): 371-378. 
Upadhyaya, H. D., Bramel, P. J., Ortiz, R. and Singh, S. 2002. Geographical patterns of diversity for morphological and agronomic traits in the groundnut germplasm collection. Euphytica, 128(2): 191-204.

Vadez, V., Hash, T. and Kholova, J. 2012. II. 1.5 Phenotyping pearl millet for adaptation to drought. Front. Physiol., 3: 386.

Van Oosterom, E. J., Weltzien, E., Yadav, O. P. and Bidinger, F. R. 2006. Grain yield components of pearl millet under optimum conditions can be used to identify germplasm with adaptation to arid zones. Field Crops Res., 96(3): 407-421.
Varalakshmi, P., Tavva, S. S. M. D., Rao, P. V. A., Rao, M. V. S., and Hash, C. T. 2012. Genetic architecture of purple pigmentation and tagging of some loci to SSR markers in pearl millet, Pennisetum glaucum (L.) R. Br. Genet. Mol. Biol., 35: 106-118. https:// doi. org/10.1590/S1415-47572012005000022.

Verma, U., Kumar, R. and Dalal, M. S. 2016. An application of multivariate techniques for divergence study in pearl millet germplasm. Stat. Appl., 14(1\&2): 63-73.

INDIASTAT, 2020. https://www.indiastat.com/ SubSection/ownloadTable?secid=1409351\&fty pe $=x \mid s$ 
$108|1-3| 10$ 